\title{
Research on Construction Technology of Boring and Implanting Bagged Crushed Stone Grouting Pile Sequentially
}

\author{
Xin-Quan WANG ${ }^{1, a,{ }^{*}}$, Yun-Liang CUI ${ }^{1, b}$, Jian-Feng LIANG ${ }^{2, c}$, \\ Shi-Min ZHANG ${ }^{1, d}$, Hui ZHANG ${ }^{3, e}$, Guang-Long $\mathrm{CHEN}^{3, \mathrm{e}}$
}

${ }^{1}$ Department of Civil Engineering, Zhejiang University City College, Hangzhou 310015, China

${ }^{2}$ Shaoxing Transportation Engineering Quality and Safety Supervision Station, Shaoxing 312000, China

${ }^{3}$ Anhui Gourgen Traffic Construction., LTD, Hefei 230000,China

awangxq@zucc.edu.cn, b cuiy@zucc.edu.cn, cliangjf2001@163.com, dzhangsm@zucc.edu.cn, e23728902@qq.com

${ }^{*}$ Corresponding author

\section{Keywords: Soft Soil Foundation, Geo-bag, Crushed Stone Grouting Pile.}

\begin{abstract}
Recently a lot of projects have adopted crushed stone grouting piles to treat the soft soil foundation. As the conventional crushed stone grouting pile construction is easy to cause cement mortar to lose and poor pile body quality, this paper innovates on the conventional crushed stone grouting pile and invents the construction technology of boring and implanting bagged crushed stone grouting pile sequentially, and introduces the technology principle, the application scope, the technological features, the construction technology and operating points of the technology.
\end{abstract}

\section{Introduction}

Soft soil spreads widely in China, as in the areas along the coast, in the middle and lower reaches of the rivers and beside the lakes, thick soil covered layers abundantly exist. As the soft soil has the defects of large moisture content, lower shear strength and poor bearing capacity, the buildings established on the soft soil area always have the problems as large after-construction subsidence volume, poor stability and extremely uneven subsidence.

Recently a lot of projects have adopted crushed stone grouting piles to treat the soft soil foundation, and a lot of experts have undertaken theoretical researches on the crushed stone piles. Zhao Minghua[1] et al. have discussed different failure modes of reinforcement crushed stone pile composite foundation, and derived the calculation formula on the ultimate bearing capacity of single reinforcement crushed stone pile according to the limit equilibrium theory under different failure modes; Wen Shiqing[2] et al. have derived the calculation method of grouting permeation influence range and the grout soil area compression modulus, verified the accuracy of the calculation formula of the grout soil area compression modulus through laboratory model experiments, and obtained the pile equivalent radius calculation formula on the grouting permeation influence through numerical fitting; Chen Changfu[3] et al. have introduced the cavity expansion theory on the soil self-weight effect influence into the bearing capacity calculation of the reinforced crushed stone pile composite foundation, established a pile group calculation model and derived the bearing capacity calculation formula of the reinforcement crushed stone pile under the action of group piles.

\section{Technology Principle and Application Scope}

(1) Technology Principle

In the construction technology of boring and implanting bagged crushed stone grouting pile sequentially, a round steel plate prefabricated pile toe or a cross steel plate prefabricated pile toe is adopted, a grouting pipe through hole is formed in the center of the pile toe, 2 to 3 steel strand through holes are embedded along the edge of the pile toe, a geo-bag and an annular latticed 
restraining body (set as required) are sequentially arranged on the outer side of the prefabricated pile toe, and a carbon fiber bag 3 to $5 \mathrm{~m}$ is adopted on the geo-bag, as in Figure 1 and Figure 2.

During the construction, according to the geological condition, the boring machine is used to drill dry soil and form a hole to the designed depth, the geo-bag and the annular latticed restraining body are fixed on the prefabricated pile toe through connecting pieces or adhesive, the grouting pipe is put into the geo-bag and extended to the bottom of the pile toe, the crushed stones with a thickness of 0.5 to $0.8 \mathrm{~m}$ are put into the geo-bag, 2 to 3 steel strands are used to lift the pile toe and the crushed stones and slowly lower them into the pile hole, and crushed stones are continuously supplemented into the geo-bag while the pile toe is being lowered; after the pile toe is lowered to the designed depth, pressure grouting is performed to the quick soil (mud) at the bottom of the pile toe through the grouting pipe, so as to form the pile tip grout solid body, which can improve the bearing capacity of the pile toe; the grouting pipe is lifted for grouting crushed stones, after the pile body meets a certain strength requirement, the pouring construction is performed to the top cover plate, after the pile body and the cover plate meet the required strength, prestress is applied to the pile body and the cover plate through the steel strands.

(2) Application Scope

The technology is applied to the foundation treating construction of soft soil foundation roads, dams, wharfs, storage yards and building foundations, particularly applicable to the soft soil foundation treatment projects with limited headroom under high-voltage lines.

\section{Technological Features}

The technology has the following feature:

(1) In an appropriate geographical condition, dry soil withdrawal or slurry supporting to bore and the steel plate pile toe with through cutting edge is also adopted, so as to greatly reduce the resistance of the soil body below and beside the pile during the lowering of the bag and improve the piling quality to a certain degree.

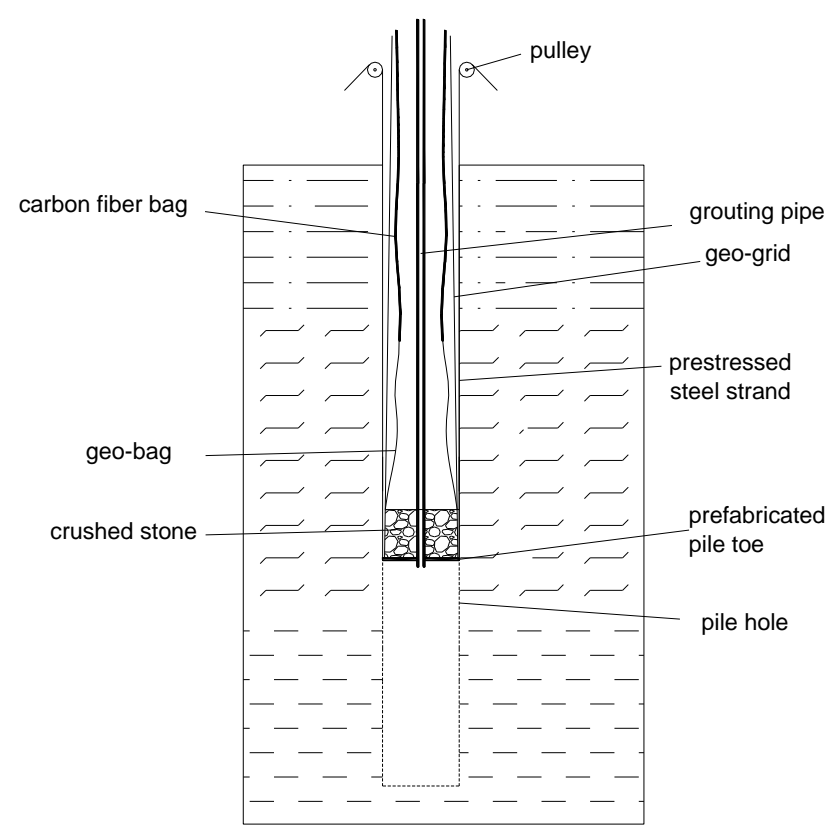

Fig. 1 Construction of Bagged Crushed Stone Grouting Pile

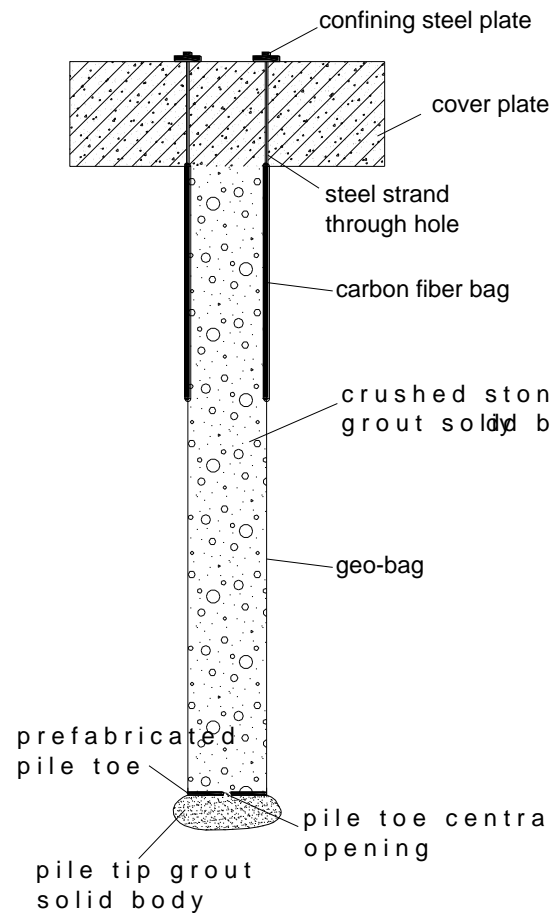

Fig. 2 Structure of Bagged Crushed Stone Pile

(2) The geo-bag and the annular latticed restraining body (set as required) on the outer side of the pile body can restrain the padding shape of the pile body, prevent the outside soil from being squeezed into the crushed stone, and prevent the pile body from cracking and necking down. 
(3) The construction machinery is light and flexible to move, the construction is quick, and large-scale organized construction is easy to carry out, and the technology is more advantageous for the soil foundation reinforcement project with limited headroom under high-voltage lines.

\section{Construction Technology Process and Operating Points}

(1) Materials

Geo-bag adopts non-woven geo-textile with a weight per unit area of $250 \mathrm{~g} / \mathrm{m}^{2}$, an equivalent aperture of 0.07 to $0.5 \mathrm{~mm}$, a tear resistance $\geq 0.9 \mathrm{kN}$, a permeability coefficient of $\mathrm{K}=1 \times 10^{-2} \sim 1 \times 10^{-3} \mathrm{~cm} / \mathrm{s}$, and a CBR burst strength $\geq 5.5 \mathrm{kN}$. Steel strand adopts the specification of $15-7 \varphi 5$. The quality of all material shall meet the design requirements and the national regulations.

(2) Operating Points

1) Dry Soil Withdrawal for Boring

A small rotary drilling rig is adopted for dry soil withdrawal for boring, in the operation, a part of the cutting edge of the spiral sleeve sleeved on the drill pipe is used to cut the soil layer in a rotary way, so as to enable the soil layer to be absorbed into the sleeve, after boring for a certain depth, the sleeve is lifted out for clearing the soil inside and then lowered again into the hole, the whole operation is reiterated until the bored depth meets the design requirement. Water can be poured into the hole while boring, so as to prevent hole collapse.

Crushed stones with a thickness of 0.5 to $0.8 \mathrm{~m}$ are thrown into the geo-bag and the prefabricated pile toe and the crushed stones are slowly lowered into the pile hole as pulled by the steel strands as in the Figure 5.2.4-1, and crushed stones are continuously poured into the geo-bag during the lowering of the pile toe. The crushed stones with 16 to $40 \mathrm{~mm}$ grading and bigger porosity are usually adopted, loaded through a dumper and slowly dumped into the geo-bag, when the crushed stones reach the level 2 to $3 \mathrm{~m}$ away from the hole opening, the machined connecting rebar connected with the cover plate shall be mounted and fixed, and the crushed stones continue to be dumped until the stones reach the level of the hole opening. The geo-bag shall be looked after by special staff during the lowering process in case that the geo-bag might rotate to be twined.

3) Pressure Grouting

The cement mortar can be mixed once the crushed stone pouring is finished, so as to grout. During grouting, the cement mortar is pressed into the quick soil (mud) at the bottom of the prefabricated pile toe through the pressure of the grouting pump, so as to form the cement mortar solid body, and the mortar is pressed between the crushed stones as in the Figure 5.2.5-2, the cement mortar gradually rises from the bottom of the hole into the gaps between the crushed stones. The grouting pressure is controlled within the range from 0.3 to $0.8 \mathrm{Mpa}$, and the mix ratio strength of mortar is determined in the laboratory according to the design requirement.

4) Supplementary Grouting

After stopping grouting for 30 to $60 \mathrm{~min}$, the cement mortar has subsided for a certain degree, then a certain amount of cement mortar shall be grouted until the cement mortar overflows from the hole opening once again, which is the secondary supplementary grouting, and the grouting is finally finished once the grouting pipe is pulled out. Flow meter, pressure gage and grouting automatic recording instrument are adopted for collecting the site data and guiding operational construction during the grouting process.

5) Prestress Applying

After the pile construction is finished, the cover plate is poured (or formed through crushed stone grouting) at the same time; after the cover plate and the pile body meet the strength requirements, the drawbench is used to selectively apply prestress to the steel strands according to the design requirement: bonded prestress can be used, or unbonded prestress can be adopted after setting the sleeve; and the restraining steel plate is arranged at the top of the cover plate, firmly and reliably mounted, and can be painted with epoxy resin anti-rusting paint for rust prevention. 


\section{Conclusions}

Through the construction application and the measured data during the specific projects, the following conclusions are reached:

(1) By boring and implanting the bagged crushed stone grouting pile to reinforce the soft soil foundation, the influence to the surrounding buildings is limited to a small degree, the construction machinery is light and flexible to move, the construction is convenient, safe and reliable, the materials are saved, the construction is quick, and large-scale organized construction is easy to carry out.

(2) In the technology, the geo-bag can be used for preventing the cement mortar from losing, the top 3 to $5 \mathrm{~m}$ of geo-bag of the pile body can be replaced by the carbon fiber bag with excellent tensile strength, which can prevent the crushed stones from being squeezed into the surrounding soil layers and ensure the construction quality of the pile body.

(3) The steel strands enable the pile toe to be lowered horizontally and stably, so as to ensure the smooth pouring of the crushed stones and avoid pile breakage, and the prestress applied to the steel strands can improve the bearing capacity of the pile body.

\section{Acknowledgement}

This material is based upon work funded by Zhejiang Provincial Natural Science Foundation of China under Grant No.LQ12E09002; Project(51308497)supported by National Natural Science Foundation of China; Zhejiang Provincial Communication Department Scientific Research Plan Project (2014H34).

\section{References}

[1]M.H. ZHAO, Q. CHEN, L. ZHANG, etc. Calculation of Bearing Capacity of Geosynthetic-encased Stone Columns, J. Journal of Highway and Transportation Research and Development. 2011, 28(8) 7-12.

[2]S.Q. WEN, H.L. LIU, Y.M. CHEN. Influence of Grout Permeation on Grouted Gravel Pile, J. Journal of Disaster Prevention and Mitigation Engineering. 2011, 28(8) 7-12.

[3]C.F. CHEN, Q.Z. LI. Calculation of bearing capacity of geosynthetic-encased cavity expansion theory, J. Journal of Hunan university natural science. 2011, 38(10) 7-12.

[4]R.F. WANG, J.H. PI.Comparative analysis of improving soft soil foundation with combining geogrids and gravel piles, J. Engineering Journal of Wuhan University. 2011, 44(1) 86-89.

[5]H. Gao, J.Y. Shi, R. Wang. Bearing capacity of solid waste ground reinforced by stone column, J. Journal of Chongqing University: Natural Science. 2011, 34(2) 113-119. 